\title{
Sastra dan Penjajahan: Membaca Karya Pengarang Tersohor Indonesia dan Malaysia
}

\author{
Rahimah A. Hamid \\ Universiti Sains Malaysia
}

\begin{abstract}
Abstrak
Makalah ini membincangkan hubungan antara sastra dengan penjajahan. Hal ini demikian karena karya sastra telah digunakan oleh pihak penjajah sebagai wahana untuk mewajarkan perlakuan penjajahan mereka ke atas peribumi dan negara jajahannya. Sebagai wacana balas, genre karya sastra bawaan penjajah Barat seperti novel, drama, cerpen dan sajak telah dijadikan alat juga oleh pengarang peribumi untuk menentang penjajahnya. Dengan melihat kepada penjajahan oleh Belanda di Indonesia dan Inggris di Malaysia, maka dua buah cerpen bertemakan politik karya Mochtar Lubis (Indonesia) berjudul "Kuli Kontrak" dan karya Keris Mas (Malaysia) berjudul Penjual Ubat Merdeka" telah dipilih untuk dijadikan materi kajian ini bagi melihat pertembungan dan pergeseran konsep dan idealisme antara peribumi tanah jajahan dengan penjajahnya. Untuk meneliti hal ini, teori kesusastraan pascakolonial digunakan sebagai teras kajian. Pada akhirnya ditemukan bagaimana karya sastra berfungsi sebagai medium yang meruntuhkan imperialisme dan kolonialisme Barat di kedua-dua buah negara ini.
\end{abstract}

Kata kunci: pascakolonial, kolonialisme, imperialisme, evolusi, pertembungan

\section{Abstract}

This paper discusses the relation between literature and colonialism. This is because literature was used by the colonial authorities as a means to justify their treatment towards the indigenous people as well as their colonies. As a counter-discourse, the literature genre of the Western colonialists such as novels, plays, short stories and poems have been used as tools by the indigenous authors themselves against the colonialists. Given the Dutch occupancy in Indonesia and the British in Malaysia, two short stories based on political theme by Mochtar Lubis (Indonesia) entitled "Kuli Kontrak" and by Keris Mas (Malaysia) entitled 'Penjual Ubat Merdeka" have been selected for this study. They are utilized to enable the collisions and frictions of the concepts and ideals between the indigenous and the colonials to be examined. In order to examine this, the postcolonial literature theory is employed as the principal theory that underlies this study. Finally, the study uncovers how literature functions as a medium to defeat Western imperialism and colonialism in both countries.

Keyword: postcolonial, colonialism, imperialism, evolution, clash 


\section{Pendahuluan}

"Sastra" dan "penjajahan" merupakan dua istilah yang tidak dapat dipisahkan. Hal ini demikian karena karya sastra adalah salah satu medium yang telah digunakan oleh penjajah pada zaman kolonial dahulu untuk membenarkan perlakuan penjajahan mereka ke atas negara-negara tanah jajahan, termasuklah ke atas Indonesia (dahulunya dikenali dengan nama Pulau-pulau Hindia Timur. Lihat Wan Ahmad D.S., 1989:13) dan Malaysia (nama asalnya Tanah Melayu). Di Indonesia, penjajah yang dimaksudkan itu ialah Belanda, manakala di Malaysia pula ialah Inggris.

Di Indonesia, karya-karya sastra yang memperlihatkan keunggulan Belanda telah ditulis oleh H. Veersema, J. Kleian, dan Bas Veth; manakala di Malaysia pula, karya-karya yang mempamerkan kehebatan Inggris ditulis oleh Joseph Conrad, Somerset Maugham, dan Anthony Burgess. Melalui karya-karya sastra ciptaan para pengarang Barat itu, mereka mewajarkan mengapa penjajahan perlu berlaku di kedua-dua buah negara di wilayah Nusantara ini. Tulisan mereka itu mendapat dukungan daripada pengarang pribumi tanah jajahan sendiri apabila terhasilnya karya sastra ciptaan Abdullah bin Abdul Kadir Munsyi pada tahun 1849 berjudul Hikayat Abdullah (Malaysia); dan oleh Marah Rusli pada tahun 1922 berjudul Sitti Nurbaja (Indonesia) yang kelihatan berpihak kepada penjajah. Sikap berpihak ini wujud mungkin berpunca daripada pendidikan sekular yang diperoleh mereka daripada penjajah Barat, atau mungkin karena pergaulan rapat mereka dengan orang Barat, atau mungkin juga karena mahu memenangi hati pihak penerbit supaya menerbitkan karya mereka karena pada ketika itu, kuasa penerbitan karya dipegang oleh pihak Barat. Hal ini menimbulkan rasa tidak puas hati dalam kalangan pengarang pribumi tanah jajahan, lantas mereka turut menggunakan sastra untuk menyatakan rasa marah, sakit hati, kesal, dendam, benci dan penolakan terhadap penjajah, lantas hal ini memunculkan korpus kesusastraan poskolonial.

Kemunculan korpus kesusastraan poskolonial ini menimbulkan suatu situasi yang sungguh menarik sekali untuk dibicarakan karena pribumi tanah jajahan telah menggunakan genre karya sastra bawaan penjajah seperti sajak, cerpen, novel dan drama sebagai alat untuk menolak, menempelak, memperlekeh dan menjatuhkan penjajah mereka. Hal ini bermakna genre sastra bawaan Barat yang diperkenalkan kepada anak pribumi tanah jajahan itu menjadi semacam "senjata makan tuan" karena telah digunakan kembali oleh pribumi tanah jajahan untuk menentang penjajahnya. Malah, penggunaan karya sastra moden bawaan penjajah Barat untuk meremehkan mereka kembali oleh pengarang pribumi sangat sesuai dilakukan karena menurut Amin Sweeney (1980:1), penjajah 
memang memandang rendah kepada karya sastra Melayu tradisional Nusantara yang disifatkannya sebagai "very poor indeed, 'pompous, pretentious and verbose.' They are full of repititions and digressions." Hal ini terjadi karena para pentadbir imperialiskolonialis Barat yang membaca, menelaah dan menyelidik karya-karya sastra Melayu tradisional Nusantara telah menggunakan tuntutan-tuntutan baharu dalam acuan Barat hingga menyebabkan karya-karya tersebut hilang kewibawaannya. Oleh sebab itu, wajarlah bagi pengarang pribumi pula untuk menggunakan genre sastra modern seperti novel, cerpen, drama dan sajak untuk menyerang penjajah mereka kembali.

\section{Puncak penjajahan Barat}

Secara umumnya, tiga perempat daripada negara-negara di dunia ini telah merasai pengalaman dijajah. Penjajah zaman purba ialah kerajaan Mesopotamia, Yunani, Romawi, Mesir, Parsi, Turki, India dan China. Bermula pada zaman Renaissance hingga ke zaman moden pula, muncul sejumlah lagi kuasa penjajah, iaitu Portugis, Rusia, Belanda, Britian, Perancis, Sepanyol, Jepun, Jerman, dan Amerika Syarikat (lihat Rahimah A. Hamid, 2010:1). Penjajahan yang dilakukan oleh kuasa-kuasa di atas bukan sekadar menguasai ruang geografi (politik) negara tanah jajahannya, tetapi juga melibatkan penguasaan ke atas ekonomi, minda, dan kebudayaan pribumi di tanah jajahannya itu.

Merujuk hanya kepada penjajahan oleh kuasa Barat ke atas negara-negara Timur, satu perkara menarik untuk direnung bersama-sama di sini ialah tentang punca penjajahan itu terjadi. "Penjajahan" dalam Bahasa Melayu yang seringkali diistilahkan sebagai imperialism ataupun colonialism dalam Bahasa Inggris, sebenarnya tidak mendukung makna yang sama (Cheah Boon Kheng, 1989:1). Makna penjajahan itu sebenarnya sesuai dengan colonialism atau kolonialisme sahaja. Walau bagaimanapun, imperialisme penting untuk merealisasikan kolonialisme. Hal ini demikian karena kata akar imperare (bahasa Latin) bermaksud memerintah. Perkataan ini berasal daripada diksi imperium yang bermaksud "daerah pemerintahan raja" (Nico Thamied R. dan M.P.B. Manus, 2000:25). Istilah ini kemudiannya berkembang dan mapan sebagai "dasar" dan "kaedah" perluasan wilayah oleh kuasa asing yang kuat ke atas negara-negara yang lemah (lihat maknanya secara lebih terperinci di dalam McLeod, 2000:9-10). Penjajahan akan menyebabkan penjajah mengenakan kuasanya dari segi politik, sosial dan ekonomi ke atas pribumi dan negara tanah jajahannya. Hal ini akan menimbulkan persaingan dalam kalangan penjajah untuk memiliki tanah jajahan yang lebih banyak dan luas, manakala dalam kalangan pribumi tanah jajahan yang punya kesedaran nasionalisme yang tinggi pula 
akan bangkit rasa benci dan marah yang mendalam terhadap penjajahnya.

Oleh yang demikian, penjajah "terpaksa" memberi alasan mengapa mereka perlu menjajah. Alasan yang paling kuat yang dikemukakan mereka didasarkan kepada teori evolusi manusia gagasan Charles Darwin melalui tulisannya yang berjudul Polygenesis of the Species. Kata mereka, orang Barat adalah bangsa yang berada di puncak evolusi, manakala manusia primitif berada pada tahap yang paling rendah dan jauh tertinggal di belakang dalam serba-serbi (Noriah Taslim, 1993: 15). Oleh yang demikian, orang Barat berkulit putih dipertanggungjawabkan Tuhan untuk menggalas beban suci (white man's burden) bagi mentamadunkan orang kulit berwarna, termasuklah orang Indonesia dan Malaysia ini.

Pandangan Darwin ini disokong kuat oleh pemikir-pemikir Barat seperti Edward Taylor, Emile Durkheim dan C.N. Morgan. Berikutan itu, Taylor telah menggagaskan pula teori Evolutionary Positivism dengan mendakwa bahawa keupayaan intelek manusia bergantung kepada rasnya.

Katanya:

For the most part this evolution was simply on increasing utilization of a brain whose structure might just as well have remained the same; as the man knows more than the child and knows better how to use his mind and knowledge, so does the civilized man knows more and think more clearly than the savage (Stocking Jr., 1968:115).

Maksudnya, terdapat hierarki dalam proses mental manusia, yang perkembangannya berlaku secara berurutan, iaitu bermula daripada tahap binatang, tidak bertamadun (savage) dan bertamadun (civilized). Berpegang kepada teori ini, maka boleh dikatakan rata-rata penjajah Barat beranggapan bahawa manusia yang tinggal di luar ruang geografi Eropah yang menjadi pusat tamadun dunia itu adalah savage dan uncivilized. Mereka percaya kepada hierarki yang mereka cipta sendiri dan uar-uarkan bahawa wujud hierarki dalam suatu ratiocultural yang memperlihatkan perbezaan yang besar antara orang Barat berkulit putih dengan manusia kulit berwarna dari bahagian dunia yang lain. Kata Taylor, yang bertamadun, berotak besar dan menjadi produk terbaik dalam evolusi organik itu adalah orang Barat berkulit putih sahaja:

In terms of which civilized men, the highest product of social evolution were large brain white men, and only large brained white men, the highest products of organic evolution were fully civilized (Maier, 1988:58).

Pandangan Taylor ini selari dengan The Great Divide Theory yang mendikotomikan proses mental manusia kulit putih dengan kulit berwarna kepada dua bahagian atau keadaan, iaitu moden-primitif; sains-mitos; rasional-tidak rasional; terbuka-tertutup (lihat Noriah Taslim, 1993:15); cerdik- 
bodoh; Selatan-Utara; dan Barat-Timur (lihat Siti Hawa Salleh, 1997:32). Ekoran daripada dikotomi mental itu, maka tercetuslah kerangka pemikiran Evolusionisme yang memperlihatkan sikap egosentrisme dan eurosentrisme orang kulit putih bahawa kononnya diri dan kelompok mereka serbaserbi lebih unggul daripada orang kulit berwarna. Fahaman yang kemudiannya disebut sebagai white supremacy ini menonjolkan pegangan orang kulit putih bahawa merekalah makhluk Tuhan yang paling istimewa, bijaksana dan berwibawa, lantas berupaya mentafsir dan menilai manusia lain. Justeru mereka perlu memikul tanggungjawab untuk mentamadunkan orang yang berada di luar daripada ruang geografi mereka itu.

Kesemua hal yang digariskan di ataslah yang dihebah-hebahkan oleh penjajah Barat sebagai sebabmengapamerekaperlumenjajah bahagian-bahagian geografi lain di dunia ini, termasuklah Indonesia dan Malaysia. Pada hal hakikatnya, mereka melakukan penjajahan adalah karena menginginkan kuasa politik ke atas negara dan bangsa lain untuk menggemilangkan dan meninggikan prestij pemerintah dan negara metropolisnya; menambahkan kekayaan ekonomi negara metropolisnya dengan mengambil dan memunggah pelbagai macam hasil bumi daripada negara yang dijajah ke negaranya; dan juga untuk mengembangkan ajaran agama Kristian. Tentang hal mengembangkan agama Kristian ini, Alfonso de Albuquerque, admiral Portugis yang menakluk Melaka berkata:

“...dan perkhidmatan yang baik untuk kita persembahkan kepada Tuhan dengan menghalau orang Islam dari negeri ini dan menghalang pengaruh golongan Muhammad daripada berkembang" (Zambry Abd. Kadir, 1998:4).

Keperluan untuk menjajah itu menjadi semakin terdesak apabila berlakunya Revolusi Industri di Britian pada tahun 1750 yang kemudiannya menyebar ke negara-negara Eropah yang lain. Revolusi Industri menyebabkan penjajah Barat semakin berlumba-lumba mencari ruang geografi negara yang kaya untuk dijajah bagi memenuhi keperluan bahan mentah dalam industri-industri yang mereka bangunkan. Apabila Revolusi Industri berakhir pada tahun 1914, lebih daripada separuh muka bumi ini telah pun terjajah kepada kuasa Barat, termasuklah Indonesia dan Malaysia yang terletak jauh di Asia Tenggara ini.

\section{Teori Kesusastraan Poskolonial}

Umum mengira bahawa Indonesia telah terjajah selama 453 tahun (1492-1945), dan Malaysia pula selama 446 tahun(1511-1957). Namun jika diteliti dengan cermat, tempoh masa penjajahan Barat yang menyeluruh itu sebenarnya bukanlah begitu. 
Hal ini demikian karena pada awalnya hanya wilayah-wilayah tertentu sahaja yang dijajah di Indonesia. Portugis memasuki Maluku pada tahun 1492, namun penguasaannya tidak menyebar ke seluruh Indonesia. Apabila rakyat Maluku di bawah pimpinan Sultan Ternate memberontak, Portugis terpaksa berundur ke Nusa Tenggara dan Timor Timur (Nico Thamiend R. dan M.P.B. Manus, 2000:26).

Belanda yang kemudiannya datang pada tahun-tahun 1602 dan 1619 dengan misi perdagangannya mula menunjukkan hasrat untuk menguasai Indonesia. Jalan untuk mencapai hasrat itu akhirnya terbuka apabila Belanda dapat menakluki Makasar pada tahun 1669. Bermula daripada tahun tersebut, Belanda mulai mencuba bersungguh-sungguh untuk mendapatkan seluruh Indonesia. Pada 1 Januari 1800 misalnya, Belanda telah menghantar satu ketumbukan angkatan tentera beserta dengan sejumlah pegawai tadbirnya ke Indonesia (Nico Thamiend R. dan M.P.B. Manus, 2000:33). Biarpun begitu, Tanah Batak hanya dapat mereka kuasai pada tahun 1907, manakala Acheh pada tahun 1913 (Mochtar Lubis, 19878:2122; Solihin Salam, 1978:8-9). Sementara itu, penjajahan awal oleh kuasa Portugis ke atas Malaysia pula hanya tertumpu di wilayah Kesultanan Melayu Melaka sahaja karena pada ketika itu penjajah sangat tertarik dengan kedudukannya yang begitu strategik sebagai kota pelabuhan dan pusat perdagangan Nusantara yang terkemuka (Emerson, 1987:79).

Oleh yang demikian, penjajahan yang menyeluruh di Indonesia hanya bermula pada tahun 1913 dan berakhir pada tahun 1945, iaitu selama 32 tahun sahaja (lihat Mochtar Lubis, 1978:21). Sedangkan penjajahan menyeluruh Inggris di Malaysia hanya berlangsung selama 48 tahun sahaja, iaitu jika dihitung dari tahun 1909 apabila negeri-negeri Melayu di bahagian utara Semenanjung yang dijajahi oleh Siam, diserahkan kepada Inggris (R. Emerson, 1987: 270).

Walau bagaimanapun, pengertian penjajahan bukanlah semata-mata tertakluk kepada penguasaan ruang geopolitik semata-mata, tetapi juga melibatkan aspek ekonomi, sosiobudaya, dan minda masyarakat. Maka sebagai penengahnya, Perjanjian Inggris-Belanda pada 17 Mac 1824 yang memperlihatkan penjajah Inggris dan Belanda berbahagi wilayah penjajahan akan digunakan sebagai garis pemula kepada penjajahan Belanda di Indonesia dan penjajahan Inggris di Malaysia. Sejak daripada tarikh berkenaan, kedua-dua kuasa penjajah itu telah mengenakan dominasi mereka ke atas pribumi tanah jajahan yang melibatkan penjajahan politik, ekonomi dan sosiobudaya. Kajian poskolonial memang melihat akan perkara-perkara tersebut, meskipun aspek ekonomi jarang disebut oleh pendiri-pendiri teori ini. 
Dalam kajian Sains Sosial pula, ilmu kolonial yang dipraktikkan penjajah dilihat lebih berfokus kepada politik karena menurut Max Weber, kuasa akan membolehkan seseorangitumenguatkuasakanapa-apasahaja kehendaknya terhadap seseorang individu atau kelompok demi mencapai sesuatu, mengawal atau mempengaruhi tingkah laku pihak lain, walaupun bertentangan dengan kemahuan pihak tersebut (Rohana Yusof, 1997:10). Dalam teori politik, kekuasaan tidak terlepas daripada kekerasan. Kekuasaan memiliki kapasiti kekerasan yang begitu besar, sehingga dianggap berbahaya kepada mereka yang terkenanya (Balendier, 1986:49). Pengenaan kuasa dan kekerasan itulah yang dipraktikkan penjajah Belanda ke atas anak pribumi Indonesia dan penjajah Inggris ke atas anak pribumi Malaysia. Cuma cara kedua-dua penjajah ini mengenakan kuasa dan kekerasan mereka agak berbeza karena penjajah Belanda kurang menggunakan diplomasi terhadap pribumi Indonesia, sedangkan penjajah Inggris begitu bijak menggunakan diplomasinya sehingga kelihatan mereka seolah-olah melayan pribumi Malaysia dengan begitu baik sekali. Anak pribumi yang terkesan dengan penjajahan Barat ini kemudiannya bangkit untuk menyatakan penentangan mereka terhadap penjajah masing-masing. Hal ini menimbulkan pergeseran hubungan antara penjajah dengan masyarakat pribumi di tanah jajahannya.
Kemerdekaan sebahagian besar daripada negara-negara tanah jajahan sebaik sahaja berakhirnya Perang Dunia Kedua menyebabkan masyarakat pribumi semakin berani menyuarakan rasa tidak puas hatinya kepada pihak penjajahnya. Kejatuhan Jepun kepada tentera berikat pada tahun 14Augustus 1945 menyebabkan Indonesia dengan pantas memproklamirkan kemerdekaannya pada 17 Augustus, tanpa sempat Belanda masuk kembali untuk menguasai Indonesia semula. Akan tetapi hasrat Malaysia untuk merdeka bersama-sama dengan Indonesia sebagai sebuah kuasa besar Melayu/Indonesia Raya hancur berkecai apabila Inggris berjaya masuk semula ke Malaysia dan merampas tampuk pemerintahan yang ditinggalkan oleh penjajah Jepun. Oleh sebab itu, Inggris kembali berkuasa selama 12 tahun lagi, sehinggalah Malaysia berjaya mencapai kemerdekaannya melalui rundingan dengan British pada 31 Augustus 1957.

Dalam tempoh tersebut lahir banyak sekali karya sastra yang memperlihatkan pergeseran hubungan antara pribumi dengan penjajahnya. Karya-karya awal di Indonesia yang menunjukkan penentangan terhadap penjajah Belanda ialah Surapati (1905) dan Salah Asuhan (1928) oleh Abdul Moies; Rasa Merdeka (1924) oleh Mas Marco Martodikromo; dan Pacar Merah Indonesia (1934) serta Panggilan Tanah Air (1940) oleh Matu Mona (Hasbullah Parindurie). Sementara itu, karya-karya awal di Malaysia 
pula yang menunjukkan penolakan terhadap penjajahan Inggris ialah Putera Gunung Tahan (1937) dan Anak Mat Lela Gila (1941) oleh Pak Sako (Ishak Haji Muhammad). Semua karya ini lahir sebelum Indonesia dan Malaysia mencapai kemerdekaannya. Oleh itu, apakah yang dimaksudkan dengan istilah karya poskolonial?

Karya poskolonial adalah satu terma yang diberikan kepada karya sastra yang memperlihatkan penolakan pribumi tanah jajahan terhadap penjajahnya. Meskipun Fanon (1961) mengaitkan aksi kekerasan dalam penolakan pribumi terhadap penjajahnya, namun ramai sarjana yang menyuarakan bahawa penolakan itu seharusnya bersifat ketegangan hubungan sahaja yang diperlihatkan melalui pertembungan-pertembungan dan pertelagahan konsep, juga ideologi antara pribumi dengan penjajahnya. Hal ini merujuk kepada model ketegangan yang disarankan oleh Ashcroft, Griffiths dan Tiffin (1989:29) yang memperlihatkan pergeseran hubungan penjajah dengan pribumi yang dijajah karena pertembungan-pertembungan konsep dan ideologi berkaitan hal-hal politik imaginatif dan sosial, yang kemudiannya turut melibatkan aspek ekonomi. Foulcher (1999:14) berpendapat, korpus ketegangan ini perlu ditandai oleh perebutan melalui minda, sifat ambivalen, mimikri dan ketidakmapanan makna. Justeru kata Mishra dan Hodge (1994:276), poskolonial itu perlu memperlihatkan:

... a politics of opposition and struggle, and problematizes the key relationship between centre and periphery.

Petikan di atas menunjukkan poskolonial tidak berfokuskan masa sebelum dan selepas sesebuah negara tanah jajahan itu mencapai kemerdekaannya, tetapi merujuk kepada ketegangan hubungan antara penjajah dengan pribumi yang dijajahnya sepanjang dan sesudah kejadian penjajahan itu berlangsung. Oleh yang demikian, Umar Junus (1998:3) yang menyetujui pandangan di atas telah menyimpulkan bahawa:

Poskolonial lebih membatasi diri kepada wacana tanpa perlu melibatkan sesuatu yang fizikal. Yang ditentang bukan penjajahan sebagai kuasa politik yang mesti ditumbangkan. Di sini tidak ada usaha penumbangan. Yang ditentang hanya wacana kolonial yang selama ini menyuarakan suara kolonial, yang melihat semuanya dari kaca mata penjajah yang berasa diri lebih tinggi dari pribumi negara yang dijajah.

Berdasarkan kepada huraian di atas, tulisan ini mahu membicarakan salah satu daripada cabang kajian karya poskolonial, iaitu berkaitan korpus yang memperlihatkan pertembungan dan pergeseran hubungan antara pribumi tanah jajahan dengan penjajahnya karena perbezaan pegangan 
dan fahaman. Dalam masa-masa tertentu, pergeseran yang wujud itu memang boleh membangkitkan ketegangan fizikal juga. Untuk melihat pergeseran hubungan dan pertembungan pegangan ini, sebuah cerpen karya Mochtar Lubis dan sebuah cerpen karya Keris Mas yang mendukung wacana poskolonial akan dibincangkan.

\section{Sekilas tentang Mochtar Lubis dan Keris Mas}

Cerpen karya Mochtar Lubis dan Keris Mas dipilih untuk dibicarakan adalah karena kedua-dua orang pengarang ini mempunyai kedudukan yang istimewa dalam jagad kesusastraan Nusantara. Kedua-dua orang pengarang ini selain tersohor di negara masing-masing, juga mempunyai latar belakang ketokohan dan kepangarangan yang lebih kurang serupa. Mochtar Lubis yang dilahirkan pada 7 Mac 1922 merupakan seorang pengarang cerpen, novel, dan pelukis yang prolifik. Sepanjang hayatnya, Mochtar Lubis telah menghasilkan beberapa buah novel seperti Jalan Tak Ada Ujung, Tak Ada Esok, Harimau! Harimau!, Maut dan Cinta, Senja di Jakarta dan beberapa yang lain. Mochtar Lubis juga telah menghasilkan sejumlah kumpulan cerpen seperti Perempuan: Kumpulan Ceritacerita Pendek, Si Jamal dan Cerita-cerita Lain, dan Bromocorah: Dua Belas Cerita Pendek. Sementara itu, Keris Mas yang dilahirkan pada 10 Jun 1922 juga merupakan seorang pengarang novel dan cerpen yang prolifik. Sepanjang hayatnya, Keris Mas telah menghasilkan beberapa buah novel seperti Saudagar Besar dari Kuala Lumpur, Rimba Harapan dan Anak Titiwangsa, juga ratusan buah cerpennya telah dikumpulkan dan diterbitkan dalam Kumpulan Cerpen Sastrawan Negara Keris Mas dan Patah Tumbuh.

Yang paling menarik, kedua-dua mereka adalah wartawan/pengarang akhbar yang juga terlibat dalam penubuhan beberapa buah persatuan penulis dan syarikat penerbitan. Mochtar Lubis merupakan antara pengasas Angkatan 45 di Indonesia (Pamusuk Eneste, 1983:59-60). Beliau juga menjadi pelopor kepada penerbitan majalah Mutiara, Mingguan Masa, akhbar Harian Indonesia Raya dan majalah Horison, serta menjadi penyumbang berita untuk majalah dan akhbar tersebut. Mochtar Lubis juga pernah menjadi wartawan Antara dan Harian Merdeka. Beliau pernah menjadi Direktur Yayasan Obor dan anggota seumur hidup Akademi Jakarta. Banyak lagi pencapaian-pencapaian Mochtar Lubis, dan ketokohannya itu terbukti melalui penganugerahan Hadiah Magsaysay oleh kerajaan Filipina kepadanya, dan juga Hadiah Piala Emas World Federation of Editors and Publishers (Rahimah A. Hamid, 2010: 10-14). Sama seperti Mochtar Lubis, Keris Mas juga merupakan pelopor kepada beberapa buah persatuan penulis. Antaranya, beliau menjadi antara pengasas kepada penubuhan Angkatan Sastrawan 50 (ASAS 
50) di Singapura pada tahun 1950 (Idros Samsudin dll, 1991:5). Sebagai wartawan/ pengarang akhbar, Keris Mas pernah bekerja dengan akhbar Utusan Melayu (Singapura), Melayu Raya, Warta Negara, Sidang Pengarang Syarikat Utusan Melayu, Pengarang Umum di Dewan Bahasa dan Pustaka (DBP) dan menamatkan tugasnya dengan cemerlang sebagai Ketua Bahagian Pembinaan dan Pengembangan Sastra DBP. Ketokohan Keris Mas menyebabkan beliau dilantik menjadi anggota pelbagai institusi kebangsaan dan kemuncak pencapaiannya ialah apabila beliau diberikan Anugerah Sastra Negara yang membawa gelar Sastrawan Negara Malaysia yang pertama.

Sebagai perbandingan, kedua-dua orang pengarang ini lahir pada tahun yang sama, mempunyai pengalaman kerja yang lebih kurang serupa, juga memiliki ketokohan yang setara. Oleh sebab kajian poskolonial ini cukup luas dan banyak cabangnya, maka hanya cerpen mereka bertemakan politik sahaja yang dipilih untuk dibincangkan di dalam tulisan ini. Cerpen tersebut ialah "Kuli Kontrak" (1982) karya Mochtar Lubis dan "Penjual Ubat Merdeka" (1991) karya Keris Mas. Kedua-dua pengarang ini dilihat telah menulis kedua-dua buah karya ini berdasarkan pengalaman hidup dan pengalaman politik masing-masing.

\section{Cerpen "Kuli Kontrak" dan "Penjual Ubat} Merdeka" sebagai Cerpen Poskolonial

Tahun-tahun menjelang kemerdekaan (selepas Perang Dunia Kedua) ketika tercetusnya revolusi di Indonesia dan Inggris kembali berkuasa di Malaysia, serta tahuntahun awal kemerdekaan di kedua-dua buah negara ini diperlihatkan oleh Mochtar Lubis dan Keris Mas dalam karya mereka sebagai tahun-tahun yang penuh ketegangan. Tahuntahun tersebut membentangkan pelbagai kisah pertembungan ideologi antara penjajah dengan pribumi tanah jajahan karena percanggahan fahaman dan budaya antara mereka.

Sebagai bangsa terjajah, anak pribumi memandang penjajah/bekas penjajahnya dengan pelbagai prasangka negatif, misalnya sebagai penjarah yang mengeksploit tenaga dan hasil bumi mereka, dan dalam masa yang sama menindas dan melakukan diskriminasi terhadap bangsa mereka. Pada pihak penjajah/bekas penjajah pula, mereka tidak berasa bersalah menakluki dan menguasai pribumi dan hasil ekonomi tanah jajahannya sebab pegangan mereka terhadap teori evolusi manusia, ideologi determinisme ras dan ideologi white men's burden memang mewajarkan mereka untuk berlaku demikian. Lantaran percaya mereka mempunyai kelebihan-kelebihan karena anugerah daripada Tuhan kepada bangsa mereka, maka penjajah/bekas penjajah menganggap bukanlah satu kesalahan jika mereka 
merampas tampuk pemerintahan daripada pemerintah pribumi, mengaut hasil buminya, memeras tenaga, dan mengacuankan kehidupan pribumi seperti yang mereka inginkan. Anak pribumi tanah jajahan/bekas tanah jajahan tidak dapat menerima ideologi penjajah itu, lantas menyebabkan hubungan mereka menjadi tegang dan bergeser.

Untuk meredakan kebencian dan penolakan pribumi terhadap mereka, Belanda dan Inggris telah menggunakan politik diplomasi dengan menggunakan pengaruh dan kewibawaan seseorang dalam kalangan masyarakat pribumi sendiri. Justeru dalam cerpen "Kuli Kontrak," Mochtar Lubis menggambarkan bagaimana Demang selaku ketua daerah dan perantara bagi penjajah dengan pribumi telah digunakan oleh penjajah untuk menangkap dan menyeksa kuli-kuli kontrak. Tujuannya adalah untuk mengabui penduduk pribumi bahawa tindakan itu sebenarnya datang daripada penjajah sendiri.

Hal ini terjadi ekoran opzichter (supervisor atau pengawas) di onderneming (perkebunan yang diusahakan secara besarbesaran) Belanda dengan berwewenang telah melakukan gangguan seksual terhadap isteri kuli-kuli kontrak di onderneming berkenaan. Opzichter tersebut berasa berhak melakukan perbuatan tersebut sebab kuli-kuli kontrak itu dan keluarga mereka bergantung hidup dengan menjadi kuli di perkebunan milik Belanda itu. Gangguan seksual yang dilakukan telah membangkitkan ketegangan hubungan antara pihak Belanda yang diwakili oleh opzichter itu dengan anak pribumi yang diwakili oleh kuli-kuli kontrak. Pada awalnya, kuli-kuli kontrak itu cuba menahan sabar karena memikirkan mereka ibarat mentimun, digolek luka, menggolek pun luka. Akan tetapi apabila gangguan itu terus berulangan, maka batas kesabaran mereka runtuh juga. Oleh itu, tiga orang kuli kontrak di onderneming itu telah bertindak menikam opzichter berkenaan:

...sebabnya terjadi penikaman terhadap opzichter Belanda itu, karena opzichter itu selalu mengganggu istri2 mereka, dan rupanya kuli2 kontrak itu sudah gelap mata tidak dapat lagi menahan hati melihat opzichter itu mengganggu istri2 mereka. Lalu mereka memutuskan ramai2 menyerang si opzichter ("Kuli Kontrak", 1982:10-12).

Oleh yang demikian, Demang dipaksa menangkap kuli-kuli kontrak itu dan mengenakan hukuman lecut (rotan) terhadap mereka tanpa sempat dibicarakan di mahkamah. Demang pada hakikatnya berpihak kepada kuli-kuli kontrak yang terdiri daripada anak bangsanya itu, tetapi dia tidak dapat berbuat apa-apa karena mendapat tekanan politik yang keras daripada Belanda.

Wacana poskolonial tersurat melalui cerpen ini apabila Demang yang tidak dapat membela nasib kuli-kuli kontrak itu menjadi 
begitu tertekan dan berada dalam keadaan ambivalen. Sebagai timbal balasnya, Demang cuba menterbalikkan pergantungannya terhadap penjajah. Lantaran dia tidak dapat melakukannya sendiri karena dibimbangi akan membahayakan nyawanya dan ahli keluarganya, maka Demang telah melarang semua anak-anaknya daripada bertuankan Belanda:

Ayah memegang tanganku, dan kemudian berkata dengan suara yang halus sekali, akan tetapi amat sungguh2, "Jika engkau besar, jangan sekali-kali engkau jadi pegawai negeri, jadi pamong praja! Mengerti?"

...sejak itu tiap ada kesempatan selalu ayah berkata supaya jangan ada seorang juapun anak2nya yang mengikuti jejaknya jadi pamong praja ("Kuli Kontrak", 1982:15).

Kecenderungan poskolonial juga terakam dengan jelas dalam cerpen ini apabila Belanda yang kononnya bangsa bertamadun dan berpegang teguh kepada konsep keadilan itu diperlihatkan bertindak menghukum lecut ketiga-tiga orang kuli kontrak yang mereka tangkap tanpa diadili terlebih dahulu. Padahal dalam undang-undang Barat, seseorang itu tidak akan dikatakan bersalah jika tidak diadili terlebih dahulu dan diputuskan sebagai bersalah oleh mahkamah. Tempelakan anak pribumi terhadap kegagalan Belanda dalam memerintah secara profesional itu tergambar melalui petikan di bawah:

"Tidak salah mereka itu," kata ibu yang rupanya berasa gusar sekali melihat kuli2 kontrak itu ditangkap.

"Mestinya opzichter jahat itu yang ditangkap," tambah ibu.

"Mengapa tidak ditangkap dia?" tanya kami anak2.

Ibu memandang kami, dan berkata dengan suara lunak, "Karena yang berkuasa Belanda! Belanda tidak pernah bisa salah."

Kata-kata isteri Demang itu adalah suara hati kebanyakan anak watan yang tertindas, tetapi tidak dapat bertindak atau berbuat apa-apa karena takut kepada dasar politik Belanda yang pada hakikatnya begitu kejam. Kata-kata itu juga memperlihatkan perasaan pribumi Indonesia yang tidak senang dan tidak boleh menerima cara pentadbiran dan layanan penjajah Belanda terhadap mereka. Lebih tajam lagi tempelakan anak pribumi terhadap penjajahnya ialah apabila opzichter Belanda yang datang dari bangsa yang kononnya hebat itu mempunyai selera seksual terhadap wanita pribumi, iaitu suatu bangsa yang dipandang lekeh oleh mereka.

Dalam cerpen "Penjual Ubat Merdeka" oleh Keris Mas pula, penjajah Inggris juga telah mempergunakan pengaruh dan wibawa pemimpin pribumi iaitu penghulu atau disebut juga sebagai penggawa untuk memenangi hati masyarakat pribumi. Ibarat 
melontar batu sembunyi tangan, penjajah Inggris telah mengenakan politik liciknya ini supaya masyarakat pribumi menganggap bahawa yang menyuruh atau melarang mereka berbuat sesuatu itu bukanlah penjajah Inggris, tetapi sebaliknya pemimpin mereka sendiri. Penjajah Inggris mendapat idea untuk melakukan demikian setelah mengkaji watak orang Melayu yang begitu patuh dan sanggup memberikan kesetiaan yang luar biasa terhadap para pemimpinnya (Syed Hussein Alatas, 1989:16). Satu hal lagi, penjajah Inggris juga tahu bahawa dalam sistem politik Melayu tradisional, pemimpin yang paling dekat dengan masyarakat massa ialah penghulu karena dia adalah perantara bagi golongan atasan dengan rakyat (Yap Beng Liang, 1989:76). Oleh yang demikian, penjajah Inggris telah mengeksploit para penghulu sebagai kuda tunggangannya. Apabila penghulu telah berjaya dikolonialisasikan, maka mudahlah bagi penjajah untuk menjadikan mereka boneka bagi melaksanakan segala agenda penjajahannya. Oleh itu, penghulu disebut oleh Keris Mas dalam cerpennya "Penjual Ubat Merdeka" sebagai:

... alat atau perkakas feudalis dan imperialis untukmenjalankan kuasa autokrasi kepada orangorang kampung supaya mereka tetap selama-lamanya tinggal tenggelam dalam lembah penghambaan dan kebodohan ("Penjual Ubat Merdeka", 1991:44).
Dalam wacana kolonial yang berteraskan faham westernism itu, penjajah memang menghendaki agar anak pribumi kekal tinggal dalam kebodohan dan berwatak hamba. Sebabnya bagi mereka, yang patut maju hanyalah orang Barat berkulit putih. Oleh itu, penghulu yang berjaya mereka kolonialisasikan telah dipergunakan untuk menindas anak watan agar tidak dapat bangkit untuk menentang penjajah Inggris. Hal ini tergambar melalui kisah watak penghulu yang diminta Inggris untuk menghalang seorang penjual ubat dari Medan, Indonesia yang bernama Muhammad daripada berjaja ubat di pekan sehari di kampung yang ditadbir olehnya. Penjajah Inggris melarang Muhammad berjaja "ubat merdeka" di kampung tersebut karena dibimbangi dapat menyuntik kesedaran kebangsaan dalam kalangan pribumi di Malaysia untuk bangun menentang penjajah Inggris. Larangan penghulu itu antara lain adalah seperti berikut:

"Jangan beli," katanya. Ini ubat politik. Merdeka, komunis dan bermacam-macam lagi disebutnya sehingga orang-orang kampung itu kelihatan ketakutan dan seorang demi seorang mereka pergi meninggalkan Muhammad dengan ubatnya ("Penjual Ubat Merdeka", 1991:43). 
"Saya penggawa di sini, berhak melarang tuan menjalankan propaganda yang dilarang kerajaan. Pekan ini tempat berniaga, bukan berpolitik" ("Penjual Ubat Merdeka", 1991:44).

Dari segi sejarah, persetujuan penghulu (penggawa) untuk menjadi alat Inggris adalah disebabkan oleh keruntuhan dan campur tangan penjajah Inggris dalam sistem politik feudal Melayu pada abad ke-19. Keruntuhan politik feudal Melayu menyebabkan kuasa perlantikan penghulu diletakkan di bawah kuasa penuh penjajah Inggris. Hal ini menunjukkan jawatan penghulu di tangan Inggris begitu birokratik. Sesiapa yang diangkat menjadi penghulu telah ditapis kesetiaannya oleh penjajah Inggris supaya menjadi alat mereka. Penghulu yang menunjukkan taat setia yang tidak berbelah bahagi kepada Inggris diberikan ganjaran tertentu seperti elaun dan pencen (Yap Beng Liang, 1989:80). Disebabkan terpesona dengan ganjaran daripada penjajah Inggris itu, maka ramailah pentadbir feudal Melayu yang sanggup diperbudakkan Inggris untuk menimpakan wacana penjajah itu ke atas anak bangsanya sendiri. Oleh sebab itu, penghulu dalam cerpen ini bersedia mengabulkan arahan penjajah Inggris untuk melarang Muhammad daripada berjualan "ubat merdeka" kepada penduduk kampung.

Muhammad sebenarnya memang seorang penjual ubat. Namun ideologi Melayu/ Indonesia Raya yang didukung olehnya membuatkan Muhammad turut menyelitkan faham kebangsaan supaya masyarakat di kampung-kampung terpencil di Malaysia pada waktu itu bangkit menentang penjajah Inggris. Sebab itulah ubatnya dinamakan "ubat merdeka". Wacana poskolonial merambah masuk ke dalam cerpen ini berdasarkan perjuangan Muhammad yang mahukan Malaysia merdeka sama seperti kemerdekaan yang dicapai oleh Indonesia pada ketika itu. Muhammad bukan mahu pribumi Malaysia menentang penghulu, tetapi sebaliknya menentang perlakuan memualkan penghulu sebagai ejen imperialis dan kolonialis Inggris. Oleh yang demikian, Muhammad tidak berhenti berniaga ubat merdekanya meskipun telah diberikan pelbagai peringatan dan tekanan oleh para penghulu di kampung-kampung yang disinggahi olehnya ketika berjaja ubat merdekanya.

Tindakan Muhammad itu ternyata merupakan wacana balikan terhadap penjajah Inggris. Hal ini demikian karena ceramahnya semakin memikat hati masyarakat pribumi, manakala ubat jualannya pula semakin laris. Dalam makna yang lebih mendalam, ubat merdeka jualan Muhammad telah mula dapat menyembuhkan masyarakat di kampungkampung terpencil yang disinggahinya daripada penyakit penjajahan Inggris. Ubatnya menjadi simbol dekolonisasi karena pribumi yang mendengar ceramahnya ketika berjualan ubat itu mula berani bangkit untuk menentang penjajah yang menjual omong kosongnya melalui penghulu-penghulu yang dilantik oleh mereka. Buktinya boleh dilihat melalui petikan di bawah:

"Merdeka! Barangkali tuantuan selalu dengar kalimat itu, 
kalimat yang sekarang jadi salam perjuangan berpuluh-puluh juta bangsa Melayu di atas dunia, kalimat yang menjadi tujuan perjuangan tiap-tiap bangsa yang tertindas dan tertakluk seperti kita ini. Dan tuantuan... kalimat yang menjadi nama kepada ubat saya ini, ubat yang nanti menyembuhkan dan memerdekakan tuan-tuan dari segala jenis penyakit" ("Penjual Ubat Merdeka", 1991:43).

Muhammad terpegun beberapa minit lamanya. Apakah ertinya ini. Ia seolah-olah tidak percaya kepada pendengarannya, lalu menyerukan "Merdeka" sekali lagi. "Tetap merdeka," jawab mereka dengan lebih gemuruh ("Penjual Ubat Merdeka", 1991:46).

Oleh itu cerpen yang menampilkan kisah penghulu sebagai ejen penjajah ini memperlihatkan dengan jelas dari sudut politik tentang unsur ketegangan dan pergeseran hubungan antara penjajah dengan pribumi tanah jajahannya. Wacana poskolonial terserlah dalam cerpen ini apabila masyarakat pribumi yang disangka oleh penjajah dapat dijadikan seperti kerbau yang dicucuk hidungnya itu telah berani bangkit untuk mendobrak wacana penjajah.

\section{Penutup}

Berdasarkan perbincangan terhadap dua buah cerpen pilihan ciptaan Mochtar Lubis dan Keris Mas di atas, maka dapatlah dirumuskan bahawa karya sastra mampu memainkan peranannya dengan berkesan sebagai wadah untuk penjajah mengenakan dominasinya ke atas pribumi tanah jajahan melalui wacana kolonialnya; dan sebagai wadah juga untuk pribumi tanah jajahan mendekolonisasikan penjajahnya melalui wacana poskolonial.

Karya kedua-dua pengarang ini dilihat telah dibangunkan melalui jurus pandang politik yang baik karena dimulakan dengan menggambarkan tujuan penjajahan Barat dan bagaimana penjajah menayangkan kehebatan kuasa mereka dalam mendominasi kehidupan masyarakat pribumi tanah jajahannya. Kemudian ditampilkan pula oleh kedua-dua pengarang ini tentang wacana balas masyarakat pribumi dalam menolak penguasaan politik penjajahnya. Hal ini menayangkan bagaimana wacana poskolonial merambah masuk ke dalam kalangan masyarakat pribumi untuk meruntuhkan dominasi penjajahnya. Berkaitan hal ini, cerpen "Kuli Kontrak" oleh Mochtar Lubis kelihatan cenderung menggambarkan aksi penentangan menggunakan kekerasan fizikal seperti yang disebut oleh Fanon itu. Aksi penentangan yang keras ini terjadi sesuai dengan cara pentadbiran penjajah Belanda 
yang juga keras terhadap masyarakat pribumi Indonesia.

Sementara itu, aksi penentangan masyarakat pribumi di Malaysia terhadap penjajahnya dalam cerpen "Penjual Ubat Merdeka" oleh Keris Mas pula lebih bersifat penentangan minda, iaitu sama seperti yang disarankan oleh kebanyakan pendukung teori kesusastraan poskolonial. Hal ini demikian karena kaedah pemerintahan penjajahan Inggris di Malaysia yang jauh lebih berdiplomasi berbanding dengan penjajahan Inggris di Indonesia.

Walau bagaimanapun, pemerintah feudal di Indonesia iaitu pamong praja dalam cerpen Mochtar Lubis diperlihatkan lebih mendalam semangat kebangsaannya berbanding dengan penghulu dalam cerpen Keris Mas yang sanggup diperalatkan sebagai tali barut penjajah.

\section{Daftar Pustaka}

Ashcroft B., Griffiths G. dan Tiffin, H. 1989. The Empire Writes Back: Theory and Practice in Post-Colonial Literature. London: Routledge.

Balendier, George. 1986. Antropologi Politik. Diterjemah oleh Y. Budisantoso. Jakarta: Rajawali.

Boon Kheng, Cheah. 1989. "Imperialisme dan Kolonialisme: Beberapa Pandangan" dalam Kolonialisme dan Imperialisme: Satu Tinjauan Sejarah. Disunting oleh Abu Talib Ahmad dan Cheah Boon Kheng. Pulau Pinang: Pusat Pengajian Ilmu Kemanusiaan, Universiti Sains Malaysia.

Foulcher, Keith. 1999. "Mimikri 'Sitti Nurbaya': Catatan untuk Faruk” dlm. Kalam, Edisi 14, hlm. 15-16.

Idros Samsudin dll. 1991. "Prosiding Seminar Serantau Pendokumentasian Bahasa dan Kesusastraan Melayu." Kuala Lumpur: Dewan Bahasa dan Pustaka, Kementerian Pendidikan Malaysia.

Keris Mas. 1991. "Penjual Ubat Merdeka" dlm. Kumpulan Cerpen Sastrawan Negara. Kuala Lumpur: Dewan Bahasa dan Pustaka

McLeod, John. 2000. Beginning Postcolonialism. Manchester: Manchester University Press.

Mishra, Vijay dan Hodge, Bob. 1994. "What is Post(-)colonialism?” dlm. Colonial Discourse and Post-Colonial Theory. Disunting oleh Patrick Williams dan Laura Chrisman. New York: Columbia University Press.

Mochtar Lubis. 1982. "Kuli Kontrak” dlm. Kuli Kontrak. Jakarta: Penerbit Sinar Harapan.

Nico Thamiend R. dan M.P.B. Manus. 2000. Sejarah. Jakarta: Penerbit Yudhistira.

Noriah Taslim. 1993. Teori dan Kritikan Sastra Melayu Tradisional. Kuala Lumpur: Dewan Bahasa dan Pustaka. 
Pamusuk Eneste. 1983. Cerpen Indonesia Mutakhir: Antologi Esei dan Kritik. Jakarta: Gramedia. Emerson, Rupert. 1987. Malaysia. Kuala Lumpur: Dewan Bahasa dan Pustaka.

Rahimah A. Hamid. 2010. Fiksyen Poskolonial: Yang Menjajah dan Dijajah. Kuala Lumpur: Dewan Bahasa dan Pustaka.

Rohana Yusof. 1997. Asas Sains Sosial dari Perspektif Sosiologi. Kuala Lumpur: Dewan Bahasa dan Pustaka.

Siti Hawa Salleh. 1997. Kesusastraan Melayu Abad Kesembilan Belas. Kuala Lumpur: Dewan Bahasa dan Pustaka.

Stocking Jr., George, W. 1968. "The Persistence of Polygenist Thought in Post-Darwinian Anthropology" dlm. Race, Culture and Evolution: Essays in the History of Anthropology. London: The Free Press.

Sweeney, Amin. 1980. Authors and Audiences in Traditional Malay Literature. Barkeley: Center for South and Southeast Asia Studies, University of Barkeley.

Syed Hussein Alatas. 1989. Mitos Peribumi Malas. Kuala Lumpur: Dewan Bahasa dan Pustaka.

Umar Junus. 1998. “(Anti/Pasca)-Kolonialisme: Persoalan (Mono/Dia)-Log”. Kertas kerja Kolokium Mempersoalkan Pasca-kolonialisme. Kuala Lumpur: Dewan Bahasa dan Pustaka.

Wan Ahmad D.S. 1989. Sejarah Islam di Indonesia. Petaling Jaya: Penerbitah al-Rahmaniah, Badan Dakwah dan Kebajikan Islam.

Yap Beng Liang. 1989. "Stratifikasi Sosial dan Masyarakat Melayu" dalam Masyarakat Melayu Struktur, Organisasi dan Manifestasi. Disusun oleh Mohd. Taib Osman. Kuala Lumpur: Dewan Bahasa dan Pustaka. 